\title{
Performance optimization in switched reluctance motor drives
}

\section{Carlos Morón ${ }^{1, a}$, Enrique Tremps ${ }^{1, b}$, Puerto Ramirez ${ }^{2, \mathrm{c}}$, Alfonso Garcia ${ }^{1, \mathrm{~d}}$, Jose Andrés Somolinos ${ }^{3, \mathrm{e}}$}

\author{
${ }^{1}$ Dpto. Tecnología de la Edificación, E.U. Arquitectura Técnica, Av. Juan de Herrera \\ ${ }^{2}$ Dpto. S.I.A., E.U. Informática, Ctra. Valencia Km. 7 \\ ${ }^{3}$ Dpto. Sistemas Oceánicos y Navales, ETSI Navales \\ Sensors and Actuators Group, Universidad Politécnica de Madrid, Spain \\ acarlos.moron@upm.es, benrique.tremps@upm.es, ${ }^{\text {c }}$ puerto@eui.upm.es,

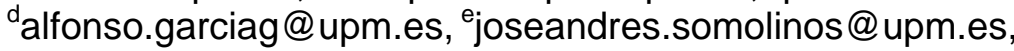

Keywords: switched reluctante motor, finite element analysis.

\begin{abstract}
In this paper, switched reluctance motors (SRM) are proposed as an alternative for electric power assisted steering (EPAS) applications. A prototype machine has been developed as very attractive design for a steering electric motor, both from a cost and size perspective. A fourphase 8/6 SRM drive is designed for a rack type EPAS which should provide a maximum force of $10 \mathrm{kN}$. Two-dimension finite element analysis is used to validate the design.
\end{abstract}

\section{Introduction}

The electrical drives play an important role on the productivity to any industry. The requirement of drives depends upon the available mains and load characteristics. Switched Reluctance Motors (SRMs) are receiving significant attention from industries in the last decade. They are extremely inexpensive, reliable and weigh less than other machines of comparable power outputs. Although the design principles of the machine are available as a concatenation of many different sources, the need for a unified, step-by-step design procedure from first principles of electromagnetism is an absolute requirement.

The very nature of the machine demands that the development of the switched reluctance motor drives requires the design of the machine and control to go hand in hand unlike any other machine. In modern cars, the use of electrical and electronic features to enhance comfort, convenience and safety has contributed to a sharp increase in power demands and in wiring harnesses. The new system has emerged as a solution to these drawbacks and provides the opportunity to replace mechanically actuated systems with systems that are based on electronically controlled electric motors [1].

The main function of an EPAS is to provide steering assistance to the driver by means of an electronically controlled electric motor. The key components of an EPAS system are a combined torque and position sensor, an electric motor with a gear reduction mechanism, an electronic control unit, and control and diagnostic algorithms that are implemented in the software [2-3]. Different types of motors have been proposed for EPAS applications [4-5].

Although the brushless DC motor and permanent-magnet synchronous motors are the bestplaced candidates, the switched reluctance motor (SRM) can be an attractive alternative due to its simple and rugged construction, its fault tolerant capability, and its high efficiency [6].

This paper presents a current controlled SRM drive for variable speed applications with efficiency optimisation. Brushless variable speed drive using switched reluctance motor (SRM) have become popular relative to other drives and represents an economical alternative in many applications. In case of SRM drive, the technical superiority of the AC drive is obtained or even enhanced at a very low cost. This is possible due to the simple motor construction and the requirement of a simple uni-polar power modulator for controlling the speed. In order to get performance oriented Drive, the accurate modelling of a Motor is to be done. The performance of 
machine can be checked with the help of Matlab/Simulink. This helps to design the Controller for the motor. Modelling can be done with the help of mathematical equations.

\section{Switched reluctance motor design}

In this work, an SRM drive is designed for rack-type EPAS systems that should provide a maximum rack force of $10 \mathrm{kN}$ and the torque-speed characteristic optimized. This requires electric motors with a mechanical output power of about $475 \mathrm{~W}$ and a torque of $2.52 \mathrm{Nm}$ at $1800 \mathrm{rpm}$. The static peak force $(10 \mathrm{kN})$ in stall conditions is forecast during the parking operation. It is required for a duty cycle of $5 \mathrm{~s}$ over $1 \mathrm{~min}$. (S3 8.5\%). The DC voltage is $42 \mathrm{~V}$ and the environmental temperature is between $-40{ }^{\circ} \mathrm{C}$ and $125^{\circ} \mathrm{C}$.

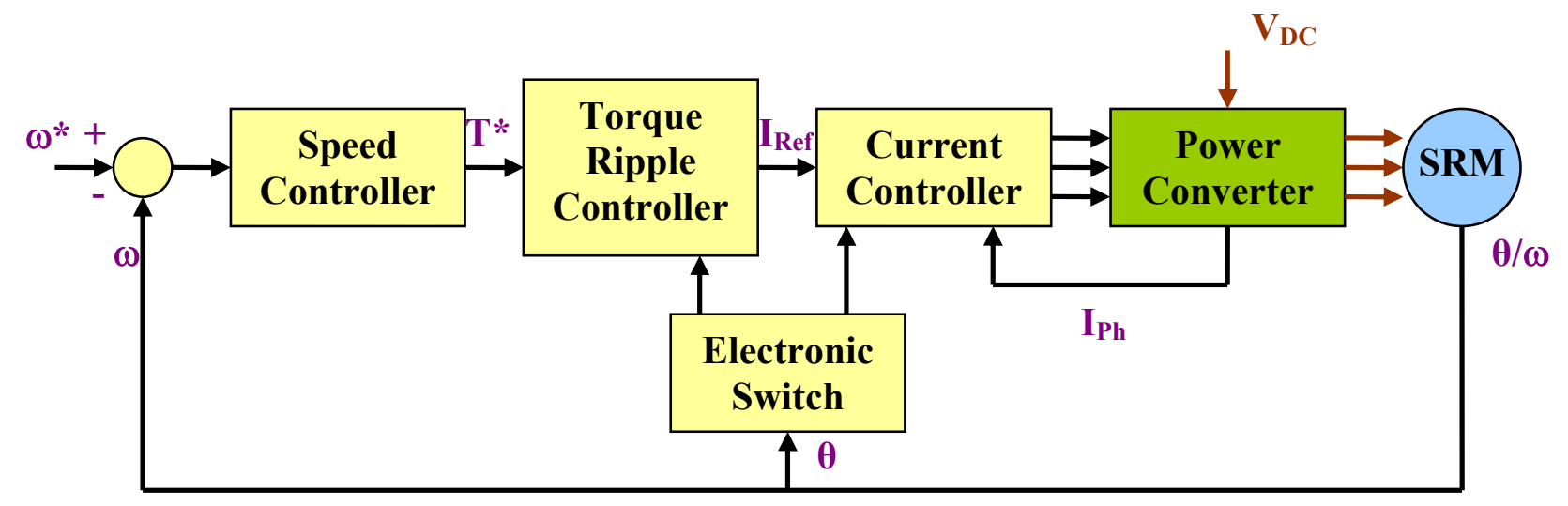

Fig. 1. Block diagram of the switched reluctance motor.

A four-phase SRM with 8 stator poles and 6 rotor poles has been chosen to reduce torque dips and to ensure better behaviour in fault conditions. The drawback of increasing the phase numbers is that more solid state switches are required in the power converter, which increases the cost and complexity of the drive. The control of the SRM drive must take into account the fact that torque ripple minimization is a strong requirement. The block diagram of the SRM drive is given in Fig. 1. The inner loop of the drive regulates the torque of the motor with the reference torque input, $T^{*}$, coming from an outer speed controller. The reference torque and the rotor position, through an electronic switcher, are used to fix the currents in the SRM phases by means of a current controller (either a hysteresis current controller or a PWM controller). Torque ripple can be minimized over a wider operating range by using electronic control techniques. The majority of these techniques use off-line or on-line computation of current profiles and a cascaded current controller. Most of these techniques are:

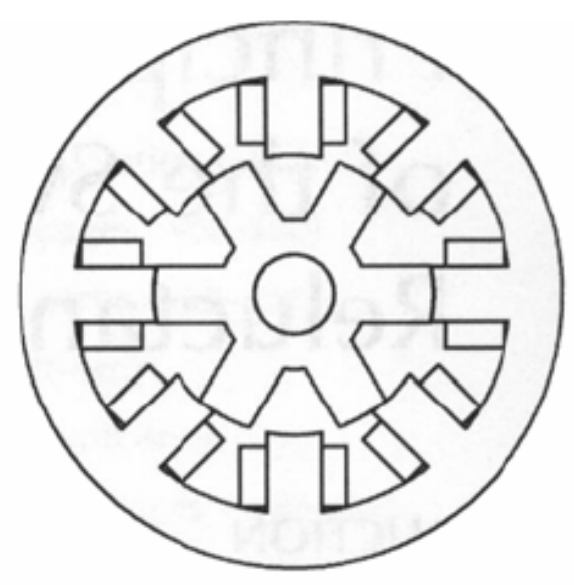

Fig. 2. SRM Geometry: 4-phase, 8 rotor poles/6 stator poles
- Indirect (controlled variable current or flux linkage): Current profiling with off-line calculation of profiles, Current profiling with on-line calculation of profiles, Flux linkage profiling with off-line calculation of profiles and Harmonic injection

- Direct (controlled variable instantaneous torque): Instantaneous torque control

The drive must also have specific controls to mitigate the effects of the faults. In the 8/6 SRM, the external diameter, including the stator frame required for the application, is $94 \mathrm{~mm}$ and the air gap is fixed to 0.35 $\mathrm{mm}$. In addition, several eco-design considerations were taken into account, namely: the number of materials should be reduced, the number of non-recyclable parts (i.e. plastics) should be minimized, the motor should be easily assembled and disassembled and the windings 
should be easy to remove. Fig. 2 shows the SRM typical structure. The power converter is an asymmetric bridge or classic converter with two switches and two diodes per phase. The switches are n-channel Power Mosfets (Vishay Siliconix SUP90N06-05L) that are easily available; the diodes are power Schottky diodes (STMicroelectronics STPS16045TV). A resolver (TAMAGAWA TS2620N27 $1 \mathrm{E} \mathrm{11)}$ is chosen as a position and speed transducer.

\section{Finite Element Analysis}

Finite Element Analysis (FEA) is used to predict the torque produced at various currents and rotor positions as well as calculate the phase inductances. The following assumptions are made in

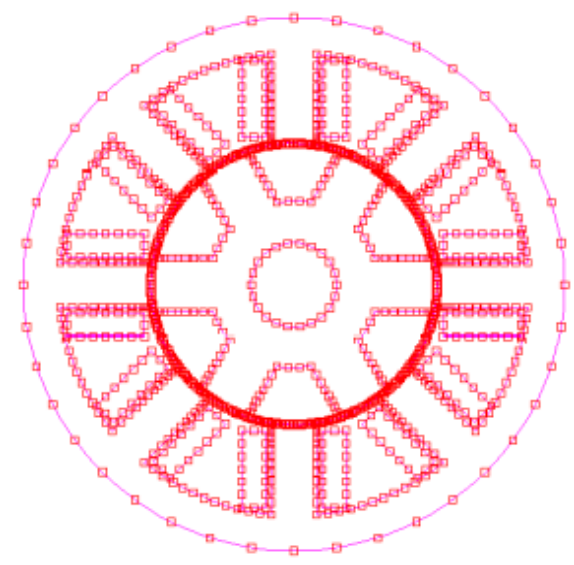

(a)

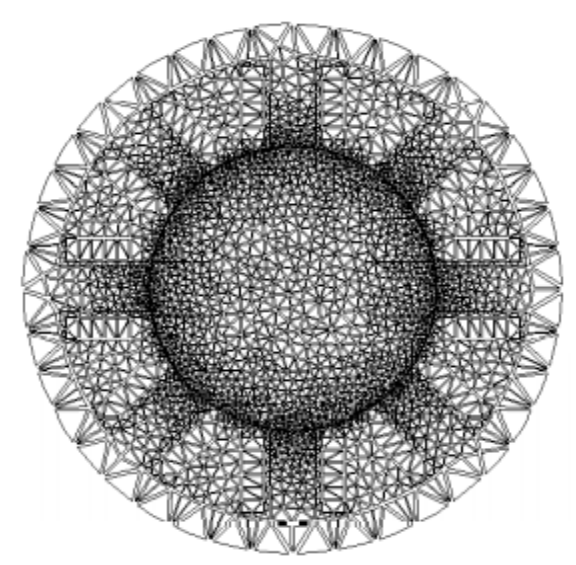

(b)

Fig. 3. Sample placement of nodes (a) and the finite element mesh (b) of an $8 / 6$ SRM.

- Magnetic vector potential A and current density J have only z-directed components.

- Magnetic field distribution inside the motor is constant along the axial direction of the motor.

- End effects are neglected.

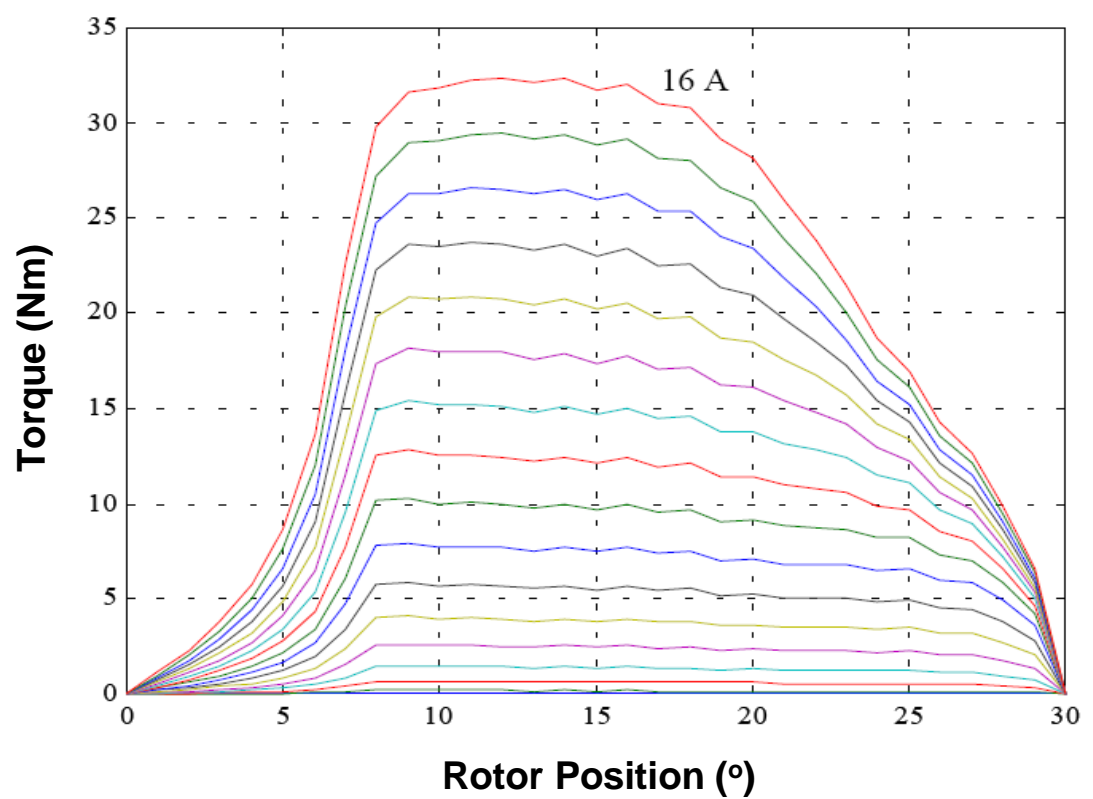

Fig. 4. Plots of torque versus rotor position for various current levels for the SRM. magnetization curves for different positions of the rotor and inductance in the aligned and unaligned position for different current values were obtained by the method of virtual work. 
The simulation of the drive (including the SRM, power converter and control) was implemented in Matlab-Simulink using the two-dimension finite element analysis results. Fig. 5 shows the voltage, phase current and torque waveforms at $900 \mathrm{rpm}$ and a current reference of 29A.

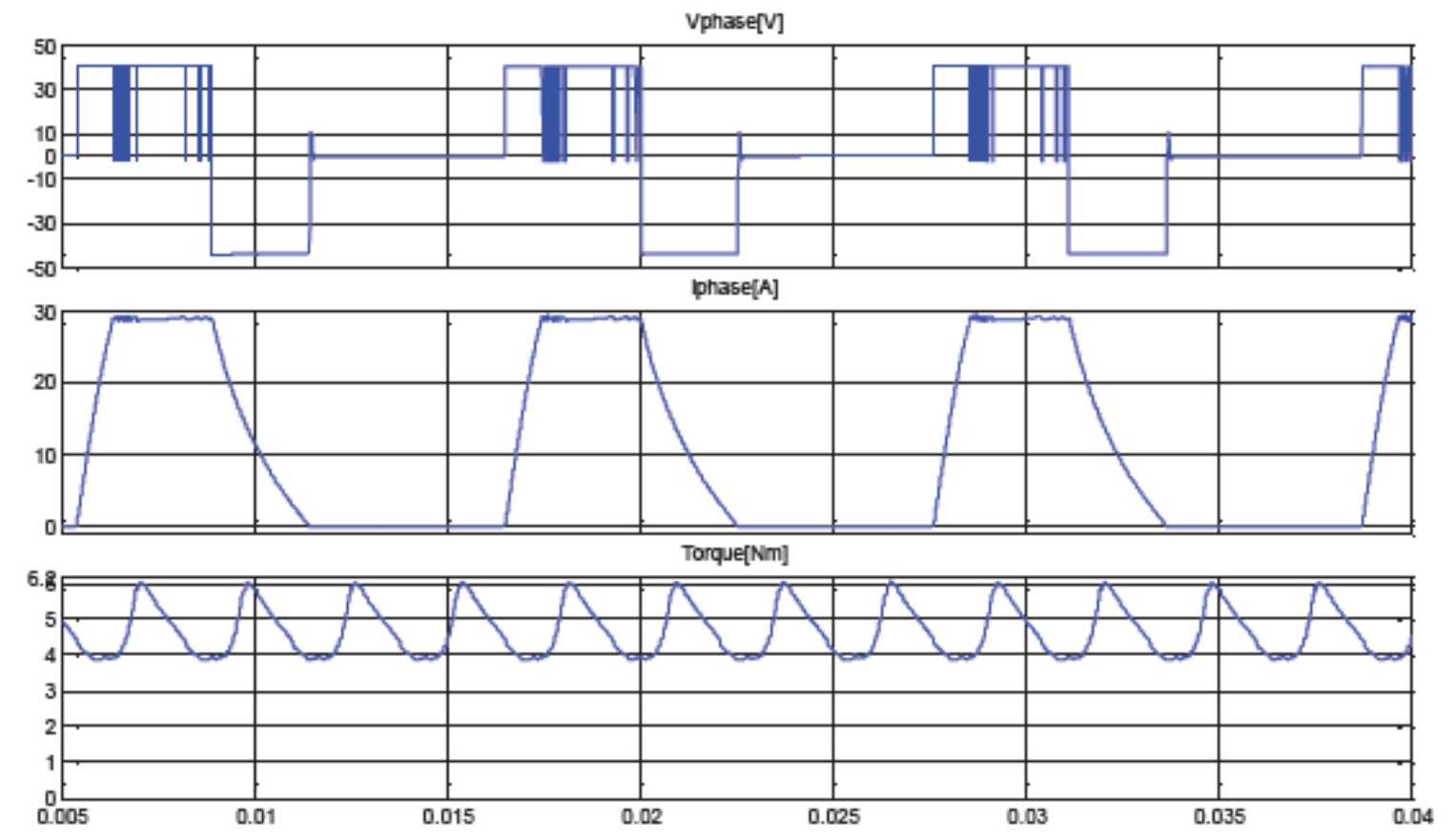

Fig. 5. Voltage, current and torque waveforms at $900 \mathrm{rpm}$ and a current reference of $29 \mathrm{~A}$.

\section{Conclusions}

In this paper, switched reluctance motor drives are proposed as an attractive alternative for EPAS applications. The $42 \mathrm{~V}$ power voltage system is very attractive in the design of the steering electric motor, both from a cost and size perspective. A four-phase 8/6 SRM is designed for rack type EPAS, which should provide a maximum rack force of $10 \mathrm{kN}$. Finite element analysis and Simulink simulations validated the SRM.

\section{References}

[1] Emadi, M. Ehsani, M. Miller, "Vehicular Electric Power Systems (Land, Sea, Air and Space Vehicles).” Marcel Dekker, 2004.

[2] J.M. Miller, A. Emadi, A.V. Rajarathnam, M. Ehsani, "Current status and future trends in more electric car power systems.” Proc. of 1999 IEEE Vehicular Technology Conference, Houston Texas, May 1999

[3] W. Ijiri and T. Tsutsui, “Technical Trends of Electric Power Steering Systems.” Koyo Engineering Journal, English Edition No.162E (2003).

[4] S. Murthy, T. Sebastian, B. Liu, "Implications of $42 \mathrm{~V}$ battery power on the design of motors for electric steering system.” SAE Technical paper 2000-00FTT-58.

[5] T. Tanaka, "Motors for electric power steering." Mitsubishi Electric ADVANCE. September 2003, pp.8-11.

[6] D. Torrey, J. Kokernak, “Power steering Brushless DC or Switched Reluctance”. Power Electronics Tech. 01.08.2002. 